\title{
PRODUÇÃO DO CONHECIMENTO NA UNIVERSIDADE: REFLEXÕES E INCUMBÊNCIAS EM TORNO DO TRABALHO DE CONCLUSÃO DE CURSO
}

\author{
GEVEHR, Daniel Luciano (Brasil, Taquara, Rio Grande do Sul) ${ }^{1 *}$; \\ FETTER, Shirlei Alexandra (Brasil, Parobé, Rio Grande do Sul) $)^{2+*}$; \\ KARPINSKI, Raquel Lemes (Brasil, Taquara, Rio Grande do Sul) ${ }^{1^{4+x}}$ \\ ${ }^{1}$ Faculdades Integradas de Taquara \\ ${ }^{2}$ Rede Municipal de Parobé \\ https://orcid.org/0000-0003-1815-4457 \\ https://orcid.org/0000-0001-5172-447X \\ https://orcid.org/0000-0003-1742-3731
}

\section{RESUMO}

Este artigo tem por objetivo discutir sobre a contribuição da pesquisa durante o processo de construção dos trabalhos de conclusão nos cursos de licenciaturas de História e Pedagogia. A temática aborda a concepção de professor pesquisador, buscando compreender a relação estabelecida durante o processo de formação. O estudo conta com doze estudantes dos cursos de História e Pedagogia de duas Instituições de Ensino Superior. Apresenta uma análise qualitativa, baseada na investigação exploratória. Já os resultados apontam que 0 processo de pesquisa contribuiu para compreensões atribuídas ao trabalho de conclusão de curso pelos entrevistados, bem como a necessidade de relação com a pesquisa entre as disciplinas. Conclui-se que há a necessidade de averiguar as condições de racionalidades que emergem da prática metodológica realizada nos cursos de licenciaturas para que a pesquisa colabore com o processo formativo.

PALAVRAS-CHAVE: Atividade de pesquisa. Formação. Conhecimento científico.

\section{KNOWLEDGE PRODUCTION IN THE UNIVERSITY: REFLECTIONS AND OUTBREAKS AROUND THE WORK OF COURSE CONCLUSION}

\section{ABSTRACT}

This article aims to present the contribution of the research during the process of construction of the conclusion work in the degree courses in History and Pedagogy. The theme addresses the design of a researcher teacher, with the purpose of understanding the relationship established during the training process. The study has twelve undergraduate students from the History and Pedagogy courses of two Higher Education Institutions. It presents a qualitative analysis, which was based on exploratory research. The results show that the research process contributed to the understandings attributed to completion of course work by the interviewees as well as the need for a relationship with the research among the disciplines. It is concluded that there is a need to ascertain the conditions of rationalities that emerge from the methodological practice carried out in the undergraduate courses so that the research collaborates with the formative process.

\section{PRODUCCIÓN DEL CONOCIMIENTO EN LA UNIVERSIDAD: REFLEXIONES E INCUMBENCIAS EN TORNO DEL TRABAJO DE CONCLUSIÓN DE CURSO RESUMEN}

Se objetiva presentar la contribución de la investigación durante el proceso de construcción de los trabajos de conclusión en los cursos de licenciaturas de Historia y Pedagogía. La temática aborda la concepción de profesor investigador con el propósito de comprender la relación establecida durante el proceso de formación. El estudio cuenta con doce estudiantes de los cursos de Historia y Pedagogía de dos Instituciones de Enseñanza Superior. Presenta un análisis cualitativo, basado

en la investigación exploratoria. Los resultados apuntan que el proceso de investigación contribuye para las comprensiones atribuidas al trabajo de conclusión de curso por los entrevistados, así como la necesidad de relación con la investigación entre las asignaturas. Se concluye que hay la necesidad de averiguar las condiciones de racionalidades que emergen de la práctica metodológica realizada en los cursos de licenciaturas para que la investigación colabore con el proceso formativo.

\section{PALABRAS CLAVE: Actividad de investigación. Entrenamiento. Conocimiento científico.}




\section{INTRODUÇÃO}

Discute-se a relação entre pesquisa e prática docente, as quais têm se constituído uma preocupação central na formação de professores na contemporaneidade. Tal inquietude provoca as universidades a uma revisão e reflexão sobre sua estrutura pedagógica e suas concepções epistemológicas, a fim de se adequarem às exigências de formação e preparação de professores habilitados para atuarem no contexto contemporâneo.

A formação do professor pesquisador tem sido acolhida por inúmeros estudiosos como uma forma de promover incremento profissional docente, para que ele possa assumir seu papel como agente de transformação social, uma vez que o seu envolvimento com a pesquisa poderá ajudá-lo a conhecer a realidade e a ter posicionamento crítico em relação ao seu fazer e às condições para o exercício da sua profissão. Perceber como ocorre essa formação e que atribuições the são conferidas são questionamentos que se apresentam de forma investigada durante as últimas décadas (ANDRÉ, 2006).

Este estudo apresenta a discussão de dados obtidos que tiveram por objetivo apresentar a contribuição da pesquisa durante o processo de construção dos trabalhos de conclusão de curso (TCCs) nas licenciaturas de História e Pedagogia. Parte-se dos fundamentos de que a constituição do sujeito, de acordo com Freire (1980), como professor pesquisador, acontece na relação dialógica, estabelecida entre as linhas teóricas que os fundamentam, os enfoques de pesquisa durante a relação com o campo prático. Nesse sentido, apresentam-se narrativas de professores, de onde foram desveladas compreensões da importância da pesquisa para a formação de futuros docentes em sua trajetória acadêmica (ANDRÉ, 2002).

A metodologia utilizada para a realização deste trabalho, além da análise qualitativa, baseou-se na investigação exploratória. A pesquisa qualitativa exploratória utiliza-se dos depoimentos e sistematização processados para, dessa maneira, facilitar o trabalho de compreensão, interpretação e inferência a que aspira a análise dos conteúdos. Para Barros e Lehfeld (2013), realizar uma análise significa buscar o sentido explicativo para os resultados da pesquisa. Seu principal critério é familiarizar-se com o fenômeno dando sentido à investigação do percurso destinado a elaborar um estudo 
sobre o envolvimento das disciplinas específicas em pesquisa, permitindo fazer relações com a elaboração dos TCCs de História e Pedagogia.

Dando sequência ao aprofundamento do assunto, solicitou-se aos professores em formação que relatassem, por meio de entrevistas, os benefícios encontrados durante o percurso acadêmico e, na sequência, refletissem sobre os fatos contribuintes ou não para a elaboração do TCC, expressando, através das entrevistas, as reflexões obtidas. Assim, a pesquisa apresentada categorizou critérios de interesse partindo da problemática que examinou a interlocução das disciplinas voltadas especificamente para a pesquisa com o TCC durante processo de formação.

Ao iniciar os trabalhos de coleta de dados, solicitou-se aos entrevistados que assinassem o termo de consentimento livre e esclarecido para que a pesquisa fosse realizada de acordo com os trâmites legais. Tendo em vista o objetivo proposto pelo estudo, os registros individuais aconteceram com doze estudantes em fase de conclusão de curso, integrados aos cursos de História e Pedagogia das Faculdades Integradas de Taquara (Faccat) e da Universidade Federal do Rio Grande do Sul (UFRGS).

No desenvolvimento inicial da pesquisa, assim como na origem e no contato com os estudantes das licenciaturas durante a coleta de informações obtidas, havia um roteiro que orientou as gravações por meio de perguntas semiestruturadas, o qual, de forma geral, questionava sobre a importância das disciplinas voltadas especificamente para a pesquisa em seu processo de formação inicial e as relações existentes com a elaboração do TCC.

O universo [amostra] pesquisado foi composto por discentes concluintes dos cursos e já atuando em escolas como docentes, estudantes que, em sua maioria, eram do sexo feminino. Dos seis alunos concluintes da Faccat, três atuavam na rede de ensino do município de Igrejinha; dois, em Sapiranga; e um, em Rolante. Já entre os membros que correspondiam ao contexto universitário da UFRGS, cinco atuavam na rede municipal de Porto Alegre e uma, no município de Cachoerinha.

Os dados coletados foram submetidos à análise de conteúdo de acordo com Moraes (1999), da qual emergiu a integração da pesquisa no ambiente acadêmico e as práticas pedagógicas interdisciplinares, ou seja, a relação dialética entre a teoria e a prática. Destarte, as referências às identidades dos participantes mantiveram-se em sigilo, de modo a não os expor, portanto os mesmos foram denominados A1, A2 e A3, 
definindo-os entre os professores em formação de História e Pedagogia da Faccat, e A1, A2 e A3, definindo-os entre os professores em formação de História e Pedagogia da UFRGS.

Buscou-se apresentar a universidade como competência às diversas atividades, oferecendo aos futuros profissionais o embasamento à ciência, desde que a formação dos profissionais da educação desperte para a pesquisa, tendo em vista que, durante toda a carreira desse docente, a pesquisa deverá apresentar-se constantemente em sua prática pedagógica, o que, para muitos graduandos, introduz a pesquisa científica mediante a realização do TCC. No campo educacional, percebe-se a necessidade de se relacionar as ações disciplinares acadêmicas no sentido de proporcionar aos professores as mais diferentes situações.

A análise sobre o processo de elaboração do TCC nos cursos de História e Pedagogia traz a reflexão sobre 0 ensino e a pesquisa proporcionada nessas licenciaturas, visto que as disciplinas de pesquisas são apresentadas no currículo como disciplinas de pesquisa educacional e as disciplinas que se envolvem com o processo científico, isto é, de elaboração do TCC, apresentam-se no último ano, culminando com a defesa do TCC. Ferreira (2009) sustenta a intenção da pesquisa como uma função criativa que reinventa as atividades atribuindo sentido e identidades pedagógicas.

Considerando-se que a inserção da pesquisa na graduação tenha sido inicialmente desvinculada da ideia de bolsa, na contemporaneidade proporcionar a vivência de práticas investigativas é um exercício das instituições de ensino superior particularmente nos cursos de licenciatura -, enquanto essa vivência tem se transformado em valioso instrumento de qualificação do trabalho do professor. A universidade é o lócus da profissionalização, pois tem como sensatez a aquisição de novos conhecimentos e, com isso, harmoniza o professor a desempenhar a profissionalização em pesquisas (ABDALLA, 2006).

\section{INTERLOCUÇÃO ENTRE TEORIA E INVESTIGAÇÃO}

Tendo consciência dos desafios que são apresentados à formação inicial de professores em nosso país, é possível evidenciar a falta de elementos que compõem as relações entre teoria e prática. A ação preparatória teórico-metodológica ensina e 
determina os conteúdos, os quais apresentam os princípios necessários à construção das atividades educativas escolares em sua totalidade, questões que valorizam a importância da pesquisa como atividade pedagógica a ser inserida no cotidiano docente, apropriando-se delas principalmente no início da formação (KIRSCH, 2007). Em vista disso, analisam-se tais questões à medida que a pesquisa científica é constituída durante o processo de formação de professores. Sobre essa questão, Kirsch (2007) nos faz pensar sobre a importância de o professor refletir sobre sua prática docente. $O$ desafio é posto no espaço acadêmico, necessitando ser trabalhado nos cursos de licenciatura não unicamente por meio dos TCCs, mas como elemento curricular fundamental nas instituições formadoras, isto é, a pesquisa na condição de elemento básico pertencente às atividades pedagógicas.

Nesse sentido, ao ingressar na universidade, tem-se em mente que as abordagens se concentram em longas jornadas de estudos, pesquisas, elaborações de trabalhos, entre eles artigos e monografias de conclusão e avaliações. Para Fazenda (2008, p. 19), "[...] o educador tem a obrigação de incentivar e propiciar a formação de novos pesquisadores". Nessa imersão, estudantes-pesquisadores vão percebendo que, além das disciplinas curriculares obrigatórias e dos estágios, existe o TCC e que esse momento da formação exige esforços e dedicação dos alunos da graduação para concluírem o curso de licenciatura.

Esse percurso de reflexão e pesquisa desde a formação inicial e certamente a partir do estímulo dado fará com que o profissional se desenvolva de modo comprometido. Os relatos latentes apresentam as reflexões sobre o emprego da pesquisa na formação de professores, os quais se fazem compreender pela problemática proeminente para as ações investigativas. Para tanto, o entendimento acerca do que é pesquisa - seu desenvolvimento e sua contribuição no processo de formação inicial - permite a descrição das percepções dos futuros professores em relação à prática de pesquisa, conforme relatou $A 1$, do curso de licenciatura em História da Faccat:

A elaboração do TCC foi um processo construtivo desde o início da graduação até o final, foi uma etapa que se concretizou pelo mesmo processo. Dentro dessa construção, foi possível entender melhor o processo de pesquisa. $O$ seu desenvolvimento se constitui durante o percurso acadêmico; partindo disso, tive a complementação lógica, que se deu a partir de sua elaboração no final do curso, em que temos a compreensão de como as coisas realmente fazem sentido.

Educação \& Formação, Fortaleza, v. 4, n. 10, p. 131-147, jan./abr. 2019

DOI: https://doi.org/10.25053/redufor.v4i10.851

http://seer.uece.br/redufor 
Ao realizar uma análise sobre as experiências relacionadas à pesquisa no decorrer da formação, a aluna apresentou em seu relato as questões realizadas no decorrer do curso, a qual, ao se deparar com o TCC, demonstrou a relação existente entre essas experiências, porém a complementação coerente deu-se na aprovação final, na conclusão do curso de licenciatura. Dando continuidade à pesquisa, A3, aluna do curso de História da Faccat, considerou o seguinte: "O processo de elaboração do TCC foi feito seguindo à risca o aprendizado adquirido durante a graduação. Com certeza, as disciplinas de pesquisas foram fundamentais para todo o caminho percorrido durante o TCC".

As consequências expressas pelos acadêmicos, tais como o exercício e a elaboração do TCC, enaltecem o entendimento sobre o prestígio e a contribuição do envolvimento com a pesquisa como método de formação inicial, sendo esse um dos entendimentos que os futuros professores expressaram em relação à prática de pesquisa. A1, estudante do curso de História da UFRGS, acrescentou: "A elaboração foi tranquila, eu já tinha contato com os professores, entre os quais estava o professor que me orientou, então não teve problemas de contato. Durante o desenvolvimento do TCC, foi que pude perceber o nexo existente entre as disciplinas".

Atividades de pesquisa continuam sendo necessárias à formação docente, visto que a imersão na prática segue em discussão. Beillerot (2001) define a pesquisa como uma questão complexa, que exige trabalho investigativo, exclusivo, quanto aos critérios apontados para defini-la. Fonseca (2008) define a pesquisa em atitudes que proporcionam as relações pedagógicas colaborativas, que envolvem as ambiências criativas de pesquisa. Os argumentos de A3, integrante do curso de História da UFRGS, ressaltaram esse processo relativo como:

\begin{abstract}
Longo e, a partir do final de 2011, até o segundo semestre de 2013, tive um bom tempo para pensar, ler, fazer o projeto, para, assim, dar sequência na escrita do TCC e apresentá-lo em dezembro de 2013. As disciplinas acabaram sendo boas, possibilitaram a escrita do projeto com cuidado, tornando possível, por exemplo, a diferenciação entre 'Problema de pesquisa', 'Objetivos', 'Recorte Temporal', 'Marco teórico', etc. A partir da clareza ou, pelo menos, do conhecimento mínimo dessas categorias, o TCC começou a ser moldado de forma sólida. É claro, as disciplinas ajudaram bastante nesse processo.
\end{abstract}

As afirmações trazidas por Ghedin (2004) expõem que a formação de professores para atuarem na educação básica torna necessário o envolvimento com a 
pesquisa e propugnam a universidade como agente de produção científica voltada ao ensino e à formação do sujeito intelectual, apontando que as disciplinas permitem a sistematização e a investigação ao longo do processo formativo. Não obstante, A1, do curso de Pedagogia da Faccat, assim se posicionou: “Durante a formação, a pesquisa foi praticamente só no TCC, fiz as disciplinas de Pesquisa e Prática 1 e 2, mas não entendi o processo".

Perante as justificavas colocadas, pode-se verificar que os acadêmicos têm a real consciência da importância e da amplitude do TCC, uma vez que este se apresenta como uma etapa essencial durante o transcurso de formação. Depois das considerações acerca do tema, Cainelli e Sanches (2008) argumentam que os professores que têm em sua formação apenas uma disciplina que aborda subsídios teórico-metodológicos por meio de estudos e pesquisas podem contribuir para a falta de preparo de alguns outros. Dando sentido a isso, apresenta-se o dizer da aluna A2, do curso de Pedagogia da instituição taquarense:

\begin{abstract}
As disciplinas de pesquisa contribuíram bastante para a elaboração do TCC, [...] proporcionaram-me abordagens amplas. Enquanto realizava aquela pesquisa, a professora que me orientava também cobrava, o que me proporcionou um aprofundamento maior. Elas me ajudaram, me orientaram a elaborar o TCC e a participar da pesquisa. Bem, na verdade, a atitude de pesquisador depende de cada um. Acontece de muitos saírem do processo de formação e não colocarem em prática aquilo que foi abordado durante o curso.
\end{abstract}

No tocante à importância das disciplinas de pesquisa relacionadas aos conteúdos específicos, segundo Tardif (2014), o conhecimento pedagógico enaltece e aprofunda a capacidade de contribuir para o desenvolvimento e consequentemente passa a exercer os saberes como compreensão do mundo em que o aluno se insere. Logo, a pesquisa como processo favorece a cultura, porque contribui para o crescimento intelectual do discente.

Lima (2010) apresenta a necessidade de incorporar o diálogo entre o ensino de ciências - e sobretudo ensinar a ensinar ciências - e o campo de ação. A2, integrante do curso de Pedagogia da UFRGS, apontou que o TCC realizado "Foi numa escola de jovens e adultos e teve como objetivo analisar a representação do aluno no Conselho Escolar, que precisava se manter atuante, cuidando das verbas, mas principalmente do Projeto Político-Pedagógico da escola". Nessa lógica, o professor pode pensar maneiras

Educação \& Formação, Fortaleza, v. 4, n. 10, p. 131-147, jan./abr. 2019

DOI: https://doi.org/10.25053/redufor.v4i10.851

http://seer.uece.br/redufor 
ímpares e diversificadas de produzir e reproduzir o conhecimento, dando-lhe novo sentido (LIMA, 2010).

\section{ENTRECRUZANDO OLHARES SOBRE AS MONOGRAFIAS DE CONCLUSÃO DE CURSO}

Ao apresentar estudos universitários em relação à elaboração do TCC e ao envolvimento dos estudantes nesse processo, Almeida (2002) salienta a participação ativa do aluno durante o processo, consequentemente dedicar-se à tarefa, durante a elaboração e execução desse trabalho, no âmbito acadêmico, demanda métodos para harmonizar a vida pessoal, articulando o trabalho e a família com a vida acadêmica. Dominando todas as investigações e trabalhos que são ofertados por todas as disciplinas para a elaboração do TCC, exige-se dos acadêmicos dedicação em tempo considerável e necessário para a execução dessa pesquisa (LENOIR, 2006).

Percebe-se que os alunos têm dificuldades para desenvolver suas pesquisas, as quais se revelam já no momento inicial da elaboração de projetos de estudos. De maneira oposta, A1, aluno do curso de História da Faccat, recordou que: "A elaboração do projeto foi tranquila, porque sempre tive bem claros os meus objetivos, o que eu queria, onde eu queria chegar. Após a conclusão do curso é que percebi que as disciplinas foram fundamentais na construção e elaboração do TCC".

Diante da construção e dos procedimentos, em que se exige a elaboração escrita, no desenvolvimento da monografia em si, ocorrem dificuldades a serem superadas, tanto no decorrer das orientações quanto no percurso do trabalho de campo. Evidencia-se isso na exposição do aluno de História da Faccat, quando disse: "Senti, por vezes, necessidade e falta de orientação. Ao chegar ao processo final do TCC, é que realmente se mergulha no assunto e se busca o entendimento de tudo. Esse foi o ponto complicado segundo a minha percepção" (A1).

Em relação ao aspecto mencionado pelo discente, concluir um curso de graduação exige e requer dedicação para realizar o que se planeja. $O$ trabalho de conclusão nada mais é do que um trabalho científico que faz parte de uma das disciplinas do curso, independentemente das demais. O suporte, que consiste no esclarecimento de dúvidas que surgem à medida que o trabalho vai ganhando forma, é

Educação \& Formação, Fortaleza, v. 4, n. 10, p. 131-147, jan./abr. 2019

DOI: https://doi.org/10.25053/redufor.v4i10.851

http://seer.uece.br/redufor 
dado pelo orientador. Concluir o curso de graduação é uma tarefa que requer dedicação, o que também proporciona momentos de trocas e experiências entre os envolvidos durante o estudo. Esse trabalho conjunto, no que se refere ao orientador, foi enaltecido da seguinte forma:

\begin{abstract}
Mesmo eu dando o melhor de mim, eu não posso deixar de ressaltar a importância que tem o papel do orientador nessa função. Posso agregar que o trabalho tem mérito pessoal, mas não seria o que foi sem a presença e a contribuição do orientador. Esse processo de construção ao lado do orientador é importante para um pesquisador, talvez um dia a gente tenha autonomia para dar os passos sozinhos, mas, durante o processo de graduação, na elaboração e conclusão do TCC, é imprescindível a presença do orientador. (A2, acadêmico do curso de História da Faccat).
\end{abstract}

As dificuldades enfrentadas durante a trajetória que os acadêmicos percorrem na elaboração do TCC dizem respeito à pesquisa como mecanismo de investigação, busca de respostas a determinado questionamento. Como também relataram os acadêmicos na sequência, foi com base na pesquisa que avançaram, ampliaram e aprofundaram os conhecimentos. Nessa direção, ao serem questionados sobre a importância da pesquisa no TCC, os estudantes apresentaram as seguintes manifestações:

\begin{abstract}
Levo em consideração o tempo de elaboração do TCC, foram nove meses de muita pesquisa, escrita, reflexão, construção e reconstrução. Quanto às disciplinas, foram praticamente todas que se relacionaram com a pesquisa. Particularmente relacionei várias disciplinas no meu TCC, principalmente Didática e Prática. (A2, acadêmico do curso de História da Faccat).
\end{abstract}

No entender de Fávero (2003), a pesquisa no campo universitário não pode ser tratada e condicionada como um "subproduto", por isso a necessidade de repensar os programas dos cursos das Instituições de Ensino Superior, para que suas ações se fundamentem, nas disciplinas de formação acadêmica, em concepções teóricas e práticas de produção científica. Quanto a essa questão, assim se colocou A3, aluna de Pedagogia da Faccat:

Considero um período importante na trajetória acadêmica a relação entre as disciplinas de Pesquisa e Prática 1 e 2. A percepção sobre a realização do TCC começa a acontecer nas disciplinas específicas de Pesquisa e Prática 1 e 2. As questões de pesquisa acontecem de forma superficial sobre o que é pesquisa, mas é realmente nas disciplinas específicas que se encontram os passos para a elaboração de pesquisas. Considero, enquanto fato negativo, que ainda são poucas as disciplinas que abrangem a pesquisa, estabelecendo-a como foco específico, o que, por vezes, em mais de 30 disciplinas, poderia ocorrer, ou seja, abordarem as questões de pesquisa. De certa forma, o curso deixou a desejar.

Educação \& Formação, Fortaleza, v. 4, n. 10, p. 131-147, jan./abr. 2019

DOI: https://doi.org/10.25053/redufor.v4i10.851

http://seer.uece.br/redufor 
Foi assim que cheguei lá no final no TCC, para, então, alcançar essa relação entre teoria e prática de pesquisa.

De acordo com Leite, Genro e Braga (2011), o que se constata na maioria das universidades é que ainda se instauram apenas modelos de ensinar e prestar serviços para a comunidade, sem uma reflexão teórica aprofundada. Consoante as referidas autoras, essa formação se configura no conhecimento e assim ocorre a produção de conhecimento científico e inovador na universidade.

\begin{abstract}
As disciplinas de Pesquisa e Prática 1 e 2 eu as realizei juntas, no mesmo ano letivo do TCC. Elas deveriam ter acontecido no início do curso, mas, por motivos pessoais, acabaram ficando para o final. Justamente consegui fazer uma relação melhor com a construção do TCC, mas o pessoal que já havia realizado a disciplina no início do curso ficou meio perdido, com dificuldade de estabelecer essa relação. (A2, acadêmica do curso de Pedagogia da Faccat).
\end{abstract}

Fávero (2003) aponta que a pesquisa científica nem sempre é parte integrante dos cursos de graduação. O conhecimento proporcionado pela universidade limita-se ao ensino transmissor e reprodutor, negando a pesquisa como estratégia pedagógica durante a graduação. "O processo de construção do TCC ocorreu de forma tranquila, tendo em vista que as disciplinas anteriores contribuíram para isso, tornando tranquila sua elaboração" (A3, acadêmica do curso de Pedagogia da UFRGS).

Com isso, os alunos passaram a exercitar sua capacidade de reflexão e senso crítico, sobretudo durante as atividades de elaboração dos trabalhos de conclusão. Porém, os futuros professores colocaram em julgamento a forma como a pesquisa foi conduzida, em sua grande parte, no decorrer do curso, havendo certo comprometimento no andamento e no relacionamento entre as disciplinas que abordavam a pesquisa. $O$ resultado da ação de pesquisar não é repentino, há uma anuência de que o acolhimento da pesquisa, como princípio educativo, acrescenta-se de maneira gradativa (DEMO, 2006). É um exercício realizado, de maneira inicial, por uma parte menos numerosa, todavia nenhuma iniciativa começa grande (GRILLO et al., 2006). À vista disso, discentes manifestaram-se a respeito da insistência em efetivar o processo de ensino e aprendizagem pela pesquisa, revelando a contribuição e o crescimento para um ensino inovador, definindo-se pelo aspecto inventor de aprendizagem autônoma. 
Quando concluí o trabalho, consegui fazer um balanço e perceber que praticamente tudo que vivi e vivenciei durante o curso foi possível colocar em prática durante o processo de TCC. Hoje posso perceber que tudo que aprendi durante os cinco anos de Faccat foi aplicado no meu TCC. (A2, acadêmico do curso de História).

A relação com o saber instigado pela pesquisa avança para o entendimento ao tomar consciência de que a memorização e a reprodução rejeitam a compreensão sobre determinado objeto. Por esse motivo, professores e alunos são sujeitos produtivos do conhecimento, e não mais objetos de reprodução do conhecimento. Não poderia ser dissemelhante em educação, porquanto a variedade de pesquisa que se realiza abordando diferentes perspectivas sobre o conjunto de problemas apresentado no campo das humanidades. Dessa maneira, a ciência produzida na área da educação favorece a interpelação acadêmica, pelo fato de que se aprimora a pesquisa pesquisando, isto é, "[...] uma ação intencional e metodologicamente estruturada na busca de uma resposta para uma pergunta previamente elaborada" (FERREIRA, 2009, p. 44).

Com isso, temos a premissa de que, além das possíveis dificuldades dos futuros professores no decorrer dos estudos do TCC, a situação possa ser inquietante quando a opção pela orientação se dá não especificamente pela aproximação do acadêmico com a temática de estudos. Feito desse modo, o ponto de vista metodológico enaltece a elaboração do estudo no processo do aprender a pesquisar. Conforme abonou A2, estudante de História da UFRGS: "Os alunos da licenciatura de História já seguem fazendo mestrado, já definem suas pesquisas como uma sequência do seu TCC, e comigo não vai ser diferente. A pesquisa que estou concluindo já está relacionada à proposta de ingresso no mestrado".

$O$ ato de pesquisar vai além da escolha de um determinado tema, urge de necessidades e curiosidades desenvolvidas pelo pensamento humano. Para Pereira e Claro (2012), a proposta exige sobre o fato e objetos manipulados reflexão, exames e adequação científica. A realidade imaginária passa a ser a ideologia que começa a fazer nexo com a realidade científica. O pensar complexo respeita a realidade constatada e com ela dialoga, entrelaçando-se à necessidade de aprender a multidimensionalidade das interações. A1, estudante de Pedagogia da Faccat, afirmou:

Com exatidão, passei a me inteirar da pesquisa científica realmente durante 0 período de realização do meu trabalho de conclusão. Posso concluir afirmando que realmente a pesquisa, para mim, só aconteceu no final. No decorrer do

Educação \& Formação, Fortaleza, v. 4, n. 10, p. 131-147, jan./abr. 2019

DOI: https://doi.org/10.25053/redufor.v4i10.851

http://seer.uece.br/redufor 
curso, percebi que ficou só na fala, nada passou dos trabalhos realizados, a partir de teorias, livros e leituras, mas nada como uma pesquisa científica que esteja relacionada à construção do conteúdo como uma bagagem teórica.

Considera-se, seguindo o entendimento de Lüdke (2001), que o acesso à elaboração prática da pesquisa, na educação, vem se aprimorando como alternativa eficaz para, na formação inicial, corroborar aprendizagens significativas, tornando-se satisfatória no sentido da reflexão e ação, incrementando o fazer pedagógico na inicialização à área da docência, em razão de fortalecer a experiência de pesquisar no decorrer das atividades acadêmicas, proporcionando, no processo de ensino e aprendizagem, a investigação. Assim, acrescentar a ação de pesquisar na academia contribui para a compreensão de que a postura investigativa precisa estar envolvida na ação docente (SLONGO et al., 2012), posição que também foi defendida por $A 1$, do curso de Pedagogia da Faccat:

\begin{abstract}
Para mim, esse processo contribuiu, porque, com as disciplinas de Pesquisa e Prática 1 e 2, cursadas bem no início do curso e agora durante o processo de elaboração do TCC, realmente consigo entender o que é uma pesquisa e o que é um trabalho científico. Esse processo vem ao encontro de todo aquele 'drama' que a gente vive durante a graduação ao saber que tem que elaborar um TCC. Realmente é difícil, mas não é impossível.
\end{abstract}

De acordo com Severino (2003), o processo a ser seguido para elaborar um trabalho de cunho científico é desenvolvido pela construção de conhecimento, por processo, e não por produto. Logo, fica evidente que as disciplinas de pesquisa têm como foco a formação do pesquisador, e não apenas um aglomerado de técnicas e manuais de como realizá-la.

Pode-se, a partir da resposta seguinte, interpretar que a pesquisa, no transcorrer do curso, é, portanto, ferramenta indispensável e deve certamente ser estimulada pelos professores, uma vez que estes atuam como responsáveis pela difusão do conhecimento. A busca e a produção do conhecimento devem ser prioridades não só na vida acadêmica como também em outros setores, assim como diz Demo (2006, p. 16): "Pesquisa é o processo que deve aparecer em todo o trajeto educativo".

Desse modo, destaca-se que a ferramenta essencial para o desenvolvimento do ensino superior é a leitura, e o professor complementa o processo como protagonista dessa integração na rotina do acadêmico, pois tudo começa por ele. Assim se posicionou uma das participantes da pesquisa sobre as disciplinas: 
Houve bastante fundamentação, a qual foi bem importante, mas, no meu ponto de vista, se as tivesse feito lá no início do curso, estariam prejudicando o desenvolvimento do meu TCC. Teve momentos, nesse período, em que me encontrei sozinha, no meu caso, é a gente mesmo que elabora, ou seja, quem faz o TCC, por causa da indisponibilidade de orientação, contudo considero um processo de grande aprendizagem. (A2, acadêmica de Pedagogia da Faccat).

Justificam Viana e Veiga (2010) que a função exercida pelo orientador deveria ser a de educador, devido a sua experiência acadêmica, compartilhando e construindo com o orientando conhecimentos, isto é, num processo de diálogo correspondente entre as partes. Dado o que foi exposto, torna-se relevante considerar o processo de orientação dentro da academia como espaço de reflexão e discussão sobre a formação continuada do orientando.

Nessa perspectiva, o professor, na contemporaneidade, caracteriza-se como orientador de todo o processo de aprendizagem e desenvolvimento do aluno acadêmico, assegurando-Ihe a produtividade do ensino; em outros termos, o professor, ao estar comprometido com a constituição integral do sujeito, desperta-lhe a capacidade de integrar-se a outros ambientes e outras formas de reinventar-se, estimulando outras características dos alunos: "Como eu já tinha essa experiência, foi tudo tranquilo durante a elaboração do TCC, mas meus colegas apresentaram muita dificuldade no entendimento do processo de pesquisa" (A3, acadêmica do curso de Pedagogia da Faccat).

As provocações e instigações que abrem espaço na elaboração e construção do conhecimento acabam levando à importância da pesquisa científica na formação acadêmica. A pesquisa, na elaboração do TCC, tem suas especificações. O TCC é uma monografia que busca realizar e aprofundar, com caráter científico, a discussão sobre um único tema, tornando-se, muitas vezes, o único trabalho científico a ser desenvolvido no decorrer da graduação, o que desenvolve um enorme problema, que passa a apontar desdobramentos negativos no processo de orientação e na qualidade do trabalho do orientando.

\section{CONSIDERAÇÕES FINAIS}

Elaborou-se sucintamente uma reflexão sobre a importância da pesquisa na formação inicial do historiador e do pedagogo, no ano de obtenção do título de licenciados, pelos cursos de Pedagogia e História da Faccat e da UFRGS com o intuito

Educação \& Formação, Fortaleza, v. 4, n. 10, p. 131-147, jan./abr. 2019

DOI: https://doi.org/10.25053/redufor.v4i10.851

http://seer.uece.br/redufor 
de descrever as percepções dos alunos a respeito da importância das disciplinas voltadas especificamente para a pesquisa em seu processo de formação inicial.

Considera-se que 0 desenvolvimento deste trabalho contribuiu para a compreensão atribuída ao TCC pelos entrevistados, bem como a relação entre as disciplinas voltadas à pesquisa. Afirma-se, de forma objetiva, que a maioria desses alunos apresentou o processo de realização do TCC nos cursos como a única exigência de pesquisa na condição de elemento científico integrador, ou seja, o foco de pesquisa deveria perpassar todo o curso, com a pré-realização da atividade de TCC.

Com base nas produções que tratam sobre o TCC desenvolvidas pelos alunos, entende-se que essa atividade demonstra algumas especificações, conforme apontaram alguns estudantes. O TCC é uma monografia na qual se possibilita a discussão sobre um determinado tema de escolha do acadêmico a ser aprofundado; em muitos casos, é o único trabalho científico a ser desenvolvido durante a graduação.

Logo, levando em conta que o TCC é uma construção intelectual do estudante, que discorre sua interpretação sobre o objeto de estudo escolhido, leitura e reflexão a respeito da situação investigada, infelizmente aponta-se que a experiência de realização desse trabalho acaba tornando-se um peso excessivo para muitos acadêmicos, pois têm dificuldades no percurso da pesquisa, o que reforça a necessidade de interação durante esse período com o orientador.

Outra questão apontada foi se a relação existente sobre a inclusão de disciplinas como Pesquisa e Prática Pedagógica 1 e 2 configura ou não por si só atividade de pesquisa. Entende-se que essas dificuldades apontadas podem estar relacionadas ao processo do trabalho desenvolvido pelos professores formadores, os quais deveriam desenvolver a habilidade de estudo com os alunos, ou seja, auxiliar e construir durante o processo a pesquisa que posteriormente se concretiza com o TCC.

De acordo com esse contexto, acredita-se ser de suma importância desenvolver a pesquisa de forma mais detalhada segundo as perspectivas da formação de professores, justamente para averiguar as condições de racionalidades que emergem da prática metodológica realizada nos cursos de licenciaturas, referências feitas pelos acadêmicos concluintes dos cursos de que a pesquisa no processo de formação colabora no processo formativo ao promover habilidades e atitudes com o intuito investigativo. 


\section{REFERÊNCIAS}

ABDALLA, M. F. B. O senso prático de ser e estar na profissão. São Paulo: Cortez, 2006.

ALMEIDA, L. S. Facilitar a aprendizagem: ajudar os alunos a aprender a pensar. Psicologia Escolar e Educacional, Campinas, v. 6, n. 2, p. 155-165, 2002.

ANDRÉ, M. O papel da pesquisa na formação e na prática dos professores. 2. ed. São Paulo: Papirus, 2002.

ANDRÉ, M. Pesquisa em educação: desafios contemporâneos. Pesquisa em Educação Ambiental, São Carlos, v. 1, n. 1, p. 43-57, 2006.

BARROS, A. J. P.; LEHFELD, N. A. S. Projeto de pesquisa: propostas metodológicas. 22. ed. Rio de Janeiro: Vozes, 2013.

BEILLEROT, J. A "pesquisa": esboço de uma análise. In: ANDRÉ, M. (Org.). O papel da pesquisa na formação e na prática dos professores. Campinas: Papirus, 2001. p. 71-90.

CAINELLI, M.; SANCHES, T. C. Saber histórico de professores nas séries iniciais: algumas perspectivas de ensino em sala de aula. História e Ensino: Revista do Laboratório de Ensino de História, Londrina, v. 14, p. 145-156, 2008.

DEMO, P. Pesquisa: princípio científico e educativo. 12. ed. São Paulo: Cortez, 2006.

FÁVERO, M. L. A. Reflexão sobre universidade, pesquisa e iniciação científica. Revista Brasileira de Política e Administração em Educação, Porto Alegre, v. 19, n. 2, p. 253-264, 2003.

FAZENDA, I. C. Dificuldades comuns entre os que pesquisam educação. In: FAZENDA, I. C. (Org.). Metodologia da pesquisa educacional. 11. ed. São Paulo: Cortez, 2008. p. 11-20.

FERREIRA, L. S. A pesquisa educacional no Brasil: tendências e perspectivas. Contrapontos, Itajaí, v. 9, n. 1, p. 43-54, 2009.

FONSECA, D. A pedagogia científica de Bachelard: uma reflexão a favor da qualidade da prática e da pesquisa docente. Educação e Pesquisa, São Paulo, v. 34, n. 2, p. 361370, 2008.

FREIRE, P. Educação como prática da liberdade. 10. ed. Rio de Janeiro: Paz e Terra, 1980.

GHEDIN, E. Implicações das reformas no ensino para a formação de professores. In: BARBOSA, R. L. L. (Org.). Trajetórias e perspectivas da formação de educadores. São Paulo: Unesp, 2004. p. 394-417.

GRILLO, M. C. et al. Ensino e pesquisa com pesquisa em sala de aula. Unirevista, Porto Alegre, v. 1, n. 2, p. 1-11, 2006.

Educação \& Formação, Fortaleza, v. 4, n. 10, p. 131-147, jan./abr. 2019

DOI: https://doi.org/10.25053/redufor.v4i10.851

http://seer.uece.br/redufor 
KIRSCH, D. B. A iniciação científica na formação inicial de professores: repercussões no processo formativo de egressas do curso de Pedagogia. 2007. $111 \mathrm{f}$. Dissertação (Mestrado em Educação) - Programa de Pós-Graduação em Educação, Universidade Federal de Santa Maria, 2007.

LEITE, D.; GENRO, M. E. H.; BRAGA, A. M. S. (Org.). Inovação e pedagogia universitária. Porto Alegre: UFRGS, 2011.

LENOIR, Y. Pesquisar e formar: repensar o lugar e a função da prática de ensino. Educação \& Sociedade, Campinas, v. 27, n. 97, p. 1299-1325, 2006.

LIMA, M. E. C. C. Uma formação em Ciências para educadores do campo e para o campo numa perspectiva dialógica. In: CUNHA, A. M. O. et al. (Org.). Convergências e tensões no campo da formação e do trabalho docente. Belo Horizonte: Autêntica, 2010. p. 167-183.

LÜDKE, M. A complexa relação entre o professor e a pesquisa. In: ANDRÉ, M. (Org.). O papel da pesquisa na formação e na prática dos professores. Campinas: Papirus, 2001. p. 27-54.

MORAES, R. Análise de conteúdo. Revista Educação, Porto Alegre, v. 22, n. 37, p. 732, 1999.

PEREIRA, V. A.; CLARO, L. C. (Org.). Epistemologia \& metodologia nas pesquisas em educação. Passo Fundo: Méritos, 2012.

SEVERINO, A. J. Metodologia do trabalho científico. 27. ed. São Paulo: Cortez, 2003.

SLONGO, I. I. P. et al. Pesquisa e formação de professores: um intrincado e instigante desafio. Revista Diálogo Educacional, Curitiba, v. 12, n. 37, p. 719-741, 2012.

TARDIF, M. Saberes docentes e formação profissional. 17. ed. Petrópolis: Vozes, 2014.

VIANA, C. M. Q. Q.; VEIGA, I. P. A. O diálogo acadêmico entre orientadores e orientandos. Educação, Porto Alegre, v. 33, n. 3, p. 222-226, 2010.

Daniel Luciano Gevehr (Brasil, Taquara, Rio Grande do Sul) - Faculdades Integradas de Taquara (Faccat)

Doutorado em História pela Universidade do Vale do Rio dos Sinos (Unisinos). É professor titular do Programa de Pós-Graduação em Desenvolvimento Regional da Faccat, onde também atua como líder do Grupo de Pesquisa Instituições, Ordenamento Territorial e Políticas Públicas para o Desenvolvimento Regional, vinculado à Faccat.

Lattes: <http://lattes.cnpq.br/0120499154280445>.

E-mail: <danielgevehr@hotmail.com>.

Educação \& Formação, Fortaleza, v. 4, n. 10, p. 131-147, jan./abr. 2019

DOI: https://doi.org/10.25053/redufor.v4i10.851

http://seer.uece.br/redufor 
Shirlei Alexandra Fetter (Brasil, Parobé, Rio Grande do Sul) - Rede Municipal de Parobé Doutoranda em Educação pela Universidade La Salle. Professora (coordenadora pedagógica) na Rede Municipal de Parobé.

Lattes: <http://lattes.cnpq.br/4125372303401355>.

E-mail: <fettershirlei@gmail.com>.

\section{Raquel Lemes Karpinski (Brasil, Taquara, Rio Grande do Sul) - Faculdades Integradas de}

\section{Taquara (Faccat)}

Doutoranda em Educação pela Universidade Federal do Rio Grande do Sul (UFRGS). Assessora pedagógica do Programa A União faz a Vida, com Educação Infantil, Ensino Fundamental, Cooperativas Escolares e Formação de Gestores. Integrante do Grupo de Estudos sobre Universidade: Inovação e Pesquisa (Geu/lpesq), vinculado à UFRGS, e do Grupo de Estudos/Pesquisa Paulo Freire, vinculado à Faccat.

Lattes: <http://lattes.cnpq.br/5322442161646439>.

E-mail: <raquelk@faccat.br>.

Recebido em 23 de janeiro de 2018.

Aceito em 28 de julho de 2018. 